\title{
Feasibility of Sub-Axial Cervical Laminar Screws, Including C7, in the Indian Population: A Study on 50 Patients Using Computed Tomography-Based Morphometry Measurements
}

\author{
Abhishek Srivastava ${ }^{1}$, Geetanjali Nanda ${ }^{2}$, Rajat Mahajan ${ }^{3}$, Ankur Nanda $^{3}$, \\ Sahil Batra ${ }^{4}$, Nirajana Mishra ${ }^{5}$, Naveen Pandita ${ }^{1}$, Harvinder Singh Chhabra ${ }^{3}$ \\ ${ }^{I}$ Department of Spine Services, Primus Hospital, New Delhi, India \\ ${ }^{2}$ Department of Radiodiagnosis, Mahajan Imaging Centre, New Delhi, India \\ ${ }^{3}$ Department of Spine Services, Indian Spinal Injuries Centre, New Delhi, India \\ ${ }^{4}$ Department of Spine Services, Caremax Superspeciality Hospital, Jalandhar, India \\ ${ }^{5}$ Economist and Data Analyst, New Delhi, India
}

Study Design: Observational study of computed tomography (CT) data.

Purpose: We performed a CT-based radiographic analysis of sub-axial cervical lamina in the Indian population to assess the feasibility of laminar screws.

Overview of Literature: Morphometric studies have been performed for populations of various ethnic groups, but none exist for Indian populations.

Methods: Cervical spine CT scans of 50 adults with a minimum slice thickness of $<2 \mathrm{~mm}(0.5-2 \mathrm{~mm})$ were obtained from the database of a single center in northern India. Measurements (e.g., length, thickness, and height) were taken in millimeters along the axial, coronal, and sagittal planes. Three measurements were made to assess laminar anatomy, namely, the translaminar/screw length, laminar thickness, and sagittal laminar height.

Results: The final sample comprised 500 laminae in 50 patients, resulting in 1,500 measurements. The mean translaminar lengths of the C3, C4, C5, C6, and C7 laminae were $19.48 \mathrm{~mm}, 19.60 \mathrm{~mm}, 19.61 \mathrm{~mm}, 20.49 \mathrm{~mm}$, and $22.85 \mathrm{~mm}$, respectively. The mean thicknesses of these cervical laminae were $3.12 \mathrm{~mm}, 2.62 \mathrm{~mm}, 2.56 \mathrm{~mm}, 3.47 \mathrm{~mm}$, and $5.20 \mathrm{~mm}$, respectively. The mean sagittal heights of these laminae were $9.38 \mathrm{~mm}, 9.80 \mathrm{~mm}, 10.12 \mathrm{~mm}, 11.31 \mathrm{~mm}$, and $13.84 \mathrm{~mm}$, respectively. Except for the C7 vertebrae, all other levels had a success rate of $<10 \%$ in the Indian population using the criteria of a laminar height of at least $9 \mathrm{~mm}$ and thickness of 4.5 $\mathrm{mm}$. Limited success was achieved at the C5, C6, and C3 levels.

Conclusions: To the best of our knowledge, the present study is the only series on the feasibility of laminar screws in the sub-axial cervical spine in the Indian population. We found that Indian patients have smaller anatomical dimensions and thus, are not suitable for laminar screws in the sub-axial cervical spine, barring $\mathrm{C}$, which is contrary to findings for populations in western and south Asian countries.

Keywords: Indian; Cervical; Morphometry; Translaminar; Screws

Received May 10, 2018; Revised Jun 16, 2018; Accepted Jul 1, 2018

Corresponding author: Abhishek Srivastava

Department of Spine Services, Primus Hospital, Chanakyapuri, New Delhi-110021, India

Tel: +91-1166206620, Fax: +91-1166206650,E-mail: abhisheksri@yahoo.com 


\section{Introduction}

Posterior instrumentation of the cervical spine and fusion with or without decompression is extensively used for the treatment of several cervical spine pathologies [1]. It may be used alone or in combination with the standard anterior cervical approach to provide immediate stabilization along with adequate decompression, allowing for early mobility [2]. The workhorse of posterior cervical instrumentation is lateral mass screw fixation, which is technically easy to place. However, due to anatomical variations, it may not be the ideal choice in several conditions, particularly at lower levels where because of size and anatomical considerations, the placement becomes technically difficult. In such cases, there is a higher pullout rate along with lower pullout strength into the bone $[3,4]$, with a slight possibility of injury to the vertebral artery in foramen transversarium. To address these issues, cervical pedicle screws were popularized by Abumi et al. [5-7]. Unfortunately, placing a cervical pedicle screw in the sub-axial spine is a much more technically demanding procedure than lateral mass fixation, and it may place both the vertebral artery and spinal cord at risk because of their close proximity to the screw. The rate of radiological malposition is also reported to be higher $[8,9]$.

In view of the above limitations, recent reports on cervical laminar screws have highlighted their simplicity and safety relative to pedicle screws [10-12]. Sub-axial cervical spine morphometry reports have noted wide anatomical variability in the dimensions of the sub-axial lamina, both in pediatric and adult populations [13-15]. Biomechanically, it is better than the lateral mass as the stress around the pedicle body complex and range of movement anticipated for the construct are smaller [16]. To date, there have been only few computed tomography (CT)-based analyses of the morphometry and feasibility of sub-axial cervical spine laminar screws $[14,17,18]$. However, to the best of our knowledge, none of these analyses were conducted in an Indian population.

The primary aim of this study was to conduct a CTbased radiographic analysis of the sub-axial cervical lamina in an Indian population to assess the feasibility of laminar screws and to identify ethnic differences in morphometry because knowledge on ethnic variations may allow limited use of this technique in this population.

\section{Materials and Methods}

After obtaining the appropriate ethical approval, 50 adult cervical spine CT scans with minimum slice thickness of $<2 \mathrm{~mm}(0.5-2 \mathrm{~mm})$ were obtained from the database of a single center in New Delhi, northern India. The raw volumetric axial images were taken, and CT reconstruction in the sagittal and coronal planes was performed using software (Radiant version 3.2.2; http://www.radiantcms.org/). Patients with incomplete cervical region scans were excluded. Cases with a demonstrable lesion in the sub-axial cervical spine in the form of a fracture, tumor, infection, inflammatory disease, or congenital malformation were also excluded.

Measurements (e.g., length, thickness, and height) were taken in millimeters along the axial, coronal, and sagittal planes. Three measurements were made to assess laminar anatomy, namely, the translaminar/screw length, laminar thickness, and sagittal laminar height.

The translaminar/screw length was measured using a technique that involves measurements of the axial plane
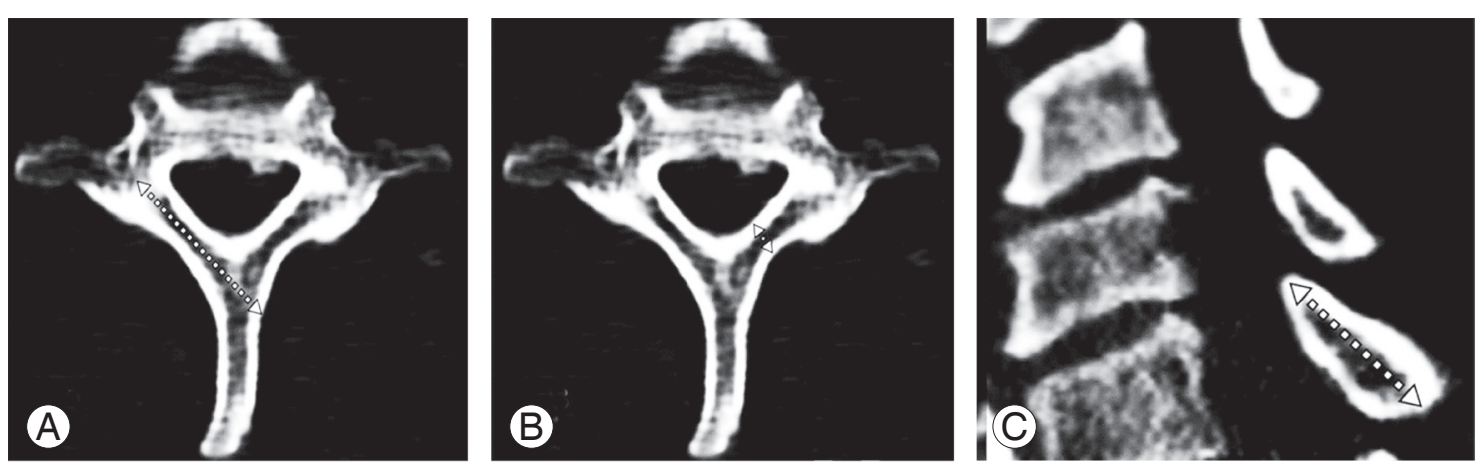

Fig. 1. Computed tomography images with representative measurement of translaminar length (A), translaminar thickness (B), and sagittal height (C). 
from the junction of the lateral mass and lamina to the contralateral outer cortex of the spinous process (Fig. 1A). The next measurement was the thickness of the lamina taken at the isthmus or narrowest part of the lamina, spanning from the ventromedial to the dorsolateral sides of the central portion bilaterally from C3 to C7 (Fig. 1B). Lastly, the sagittal measurement or laminar height was measured bilaterally along the parasagittal plane from C3 through C7, which was defined as the most rostral point of the lamina, terminating at the most caudal portion of the lamina of the same vertebrae on the sagittal plane (Fig. 1C). The three measurements were performed after the two authors agreed on the image based on the above criteria using PACS software (Radiant) to achieve consistent observations.

Descriptive statistics, including the mean, standard deviation, and range, were calculated. Differences in measurements of the right and left laminar dimensions, along with sex variation, were assessed using Student $t$-tests. The literature was then reviewed along with the resulting data to identify variations and their amenability to instrumentation.

\section{Results}

\section{Patient demographic data}

Fifty (25 males, 25 females) cervical spine CT scans were evaluated in this study. The mean age of male patients was $54 \pm 12.1$ years (range, $31-75$ years) and the mean age of female patients was $49.2 \pm 15.2$ years (range, $22-80$ years). Age did not significantly differ between sexes $(p=0.45)$.

\section{Morphometric analysis}

The final study sample comprised 500 laminae in 50 patients, giving 1,500 measurements. The mean translaminar lengths of the C3, C4, C5, C6, and C7 laminae were $19.48 \mathrm{~mm}, 19.60 \mathrm{~mm}, 19.61 \mathrm{~mm}, 20.49 \mathrm{~mm}$, and 22.85 $\mathrm{mm}$, respectively. The mean thicknesses of these cervical laminae were $3.12 \mathrm{~mm}, 2.62 \mathrm{~mm}, 2.56 \mathrm{~mm}, 3.47 \mathrm{~mm}$, and $5.20 \mathrm{~mm}$, respectively. The mean sagittal heights of these laminae were $9.38 \mathrm{~mm}, 9.80 \mathrm{~mm}, 10.12 \mathrm{~mm}, 11.31 \mathrm{~mm}$, and $13.84 \mathrm{~mm}$, respectively (Table 1 ).

Measurements for individual levels for both sexes were done as depicted in Table 2 . There were statistically significant differences in laminar thickness for males and fe-
Table 1. Mean morphometric (i.e., translaminar length, thickness, height, and sagittal-diagonal) measurements at each vertebral level

\begin{tabular}{lccc} 
Level & $\begin{array}{c}\text { Lamina } \\
\text { length }\end{array}$ & $\begin{array}{c}\text { Laminar } \\
\text { thickness }\end{array}$ & $\begin{array}{c}\text { Laminar sagittal } \\
\text { height }\end{array}$ \\
C3 & $19.48 \pm 2.03$ & $3.12 \pm 0.77$ & $9.38 \pm 1.59$ \\
C4 & $19.60 \pm 2.08$ & $2.62 \pm 0.65$ & $9.80 \pm 1.44$ \\
C5 & $19.61 \pm 2.13$ & $2.56 \pm 0.66$ & $10.12 \pm 1.54$ \\
C6 & $20.49 \pm 2.41$ & $3.47 \pm 0.88$ & $11.31 \pm 1.82$ \\
C7 & $22.85 \pm 2.38$ & $5.20 \pm 0.79$ & $13.84 \pm 1.37$ \\
\hline
\end{tabular}

Values are presented as mean \pm standard deviation.

males, particularly at C7 ( $p=0.0017)$. In the morphometric values, no statistically significant differences were noted between the right and left sides at all levels.

\section{Success rate of screw placement}

As depicted in Table 3, the success rate of screw insertion was calculated using the criteria of Chern et al. [13], Shin et al. [17], and Alvin et al. [18]. Besides the C7 vertebrae, all other levels had success rates of $<10 \%$ in the Indian population using the criteria of a laminar height of at least $9 \mathrm{~mm}$ and thickness of $4.5 \mathrm{~mm}$. The $\mathrm{C} 4$ did not allow placement of laminar screws by the criteria, whereas limited success was noted at the $\mathrm{C} 5, \mathrm{C} 6$, and $\mathrm{C} 3$ levels.

\section{Discussion}

Laminar screws were popularized by Wright [19] for $\mathrm{C} 2$ as a safer alternative to pedicle screws in the $\mathrm{C} 1-\mathrm{C} 2$ constructs. This technique allows direct insertion under regular vision, eliminating the need for navigation or fluoroscopy, and is not limited by the positioning of vascular structures with good biomechanical stability. Encouraged by the use of C2 laminar screws, Hong et al. [14] extended their use in the sub-axial spine. Subsequently, many authors have reported the feasibility and use of this technique in a limited way, but none have done so in the context of Indian patients. Because ethnic variation has been reported for anatomical structures, such as pedicles and condyles [20-22], this study focused on the ability to apply this technique to Indian populations.

\section{Morphometric Measurements}

Laminar thickness, which is the most critical dimension 


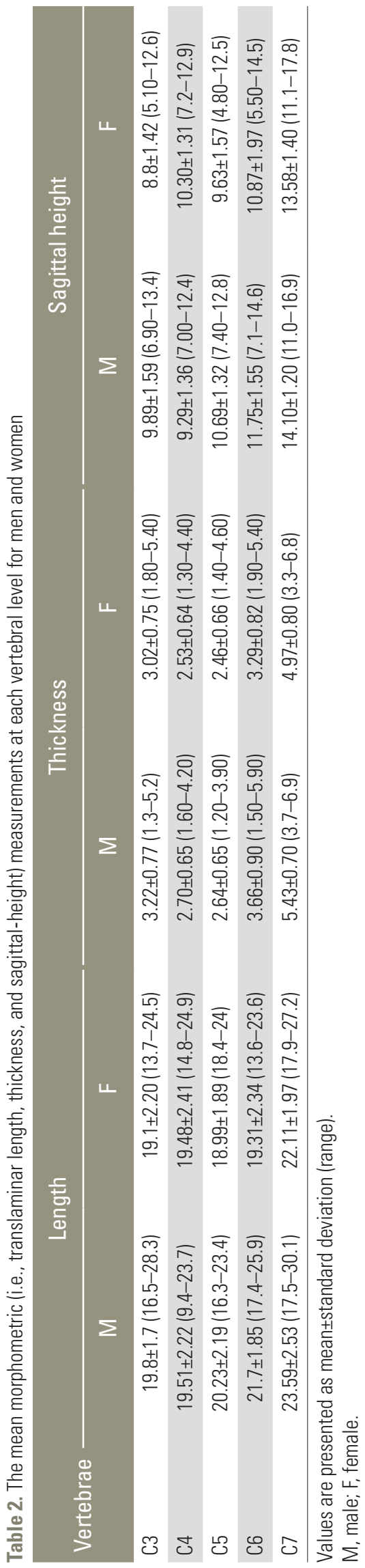

for placing laminar screws, was at its maximum at C7 ( $>5$ $\mathrm{mm})$ and $<3 \mathrm{~mm}$ at all other levels, barring $\mathrm{C} 3$ where the mean was $3.12 \mathrm{~mm}$. This is mostly in line with reports by $\mathrm{Xu}$ et al. [23] and Chern et al. [13] of pediatric patients, but lower than the values reported by Alvin et al. [18] where the average thickness was $>4 \mathrm{~mm}$ at all sub-axial cervical levels. This finding underscores the wide variation in anatomy. Males were significantly more likely than females to have a laminar thickness that allows safe placement of laminar screws at C7.

The laminar length, which determined the length of laminar screw, was smaller than previously reported values. The mean was consistently $<24 \mathrm{~mm}$ at all levels, including C7. This is important as a $24-\mathrm{mm}$ screw length was used in biomechanical and anatomical studies on laminar screws $[14,24]$, and these may thus, not be suitable for Indian patients as none would qualify for this technique. This finding warrants further biomechanical research focused on the effect of screw length and pullout strength/biomechanical stability in the above technique.

The laminar height was $>9 \mathrm{~mm}$ at all levels in the subaxial spine, which should allow bilateral placement of adequately sized screws, assuming the commonly used screw dimensions of $3.5 \mathrm{~mm}$. The maximum sagittal height was noted at C7, and the mean values decreased moving from the caudal to cephalad level. Our findings were similar to those by Alvin et al. [18] for mean sagittal diagonal measurements, but with consistent measurements of $>10 \mathrm{~mm}$ at all levels.

\section{Anatomical feasibility of screw placement}

The reported feasibility of placing $3.5 \mathrm{~mm}$ laminar screws, based on anatomical measurements, varies across studies. In this study, we applied the criteria used by Chern et al. [13], Shin et al. [17], Alvin et al. [18] as outlined in Table 3. Based on these criteria, laminar screws are not feasible at $\mathrm{C} 3, \mathrm{C} 4, \mathrm{C} 5$, and $\mathrm{C} 6$; $\mathrm{C} 7$ was the only level where the acceptability was $>80 \%$ for at least two criteria. This resonates with work by Cardoso et al. [24] that reported 100\% feasibility in C7 lamina in nine patients in a series for 3.5$\mathrm{mm}$ screws. The study by Shin et al. [17] reported higher feasibility of C7 laminar screws and screws at other levels compared to our study. However, they did not recommend placing laminar screws at $\mathrm{C} 4$ or $\mathrm{C} 5$, and recommended extreme caution at C3 and C6 (approximately $30 \%$ ). This emphasizes the anatomical limitations of lami- 
Table 3. Feasibility of laminar screw using various published criteria

\begin{tabular}{|c|c|c|c|}
\hline Variable & $\begin{array}{l}\text { Feasibility using criteria of } \\
\text { Chern et al. [13] }\end{array}$ & $\begin{array}{l}\text { Feasibility using modified } \\
\text { criteria of Shin et al. [17] }\end{array}$ & $\begin{array}{c}\text { Feasibility using criteria of } \\
\text { Alvin et al. [18] }\end{array}$ \\
\hline \multicolumn{4}{|l|}{ Criteria } \\
\hline Laminar height (mm) & $\geq 9$ & - & $\geq 7$ \\
\hline Laminar thickness (mm) & $\geq 4.5$ & $\geq 4.0$ & $\geq 4.5$ \\
\hline Screw length (mm) & - & 25 & $\geq 7$ \\
\hline \multicolumn{4}{|l|}{ Vertebral level (\%) } \\
\hline C3 & 6 & 0 & 7 \\
\hline $\mathrm{C} 4$ & 0 & 0 & 0 \\
\hline $\mathrm{C5}$ & 1 & 0 & 1 \\
\hline C6 & 8 & 1 & 13 \\
\hline $\mathrm{C7}$ & 83 & 12 & 83 \\
\hline
\end{tabular}

nae in Indian patients and possible ethnic differences.

\section{Limitations}

The study investigated a limited number of patients and their CT scans to assess the morphometry of the laminae of the sub-axial cervical spine in Indian patients. The dataset mainly comprised patients from northern India and may thus, not represent the full spectrum of India's ethnic diversity. Moreover, we did not perform a computer simulation and relied on criteria published by other authors to assess the feasibility of the screws. Finally, height, weight, and body mass index were not considered in this study. Despite these shortcomings, this is the first study to assess this novel technique in an Indian population.

\section{Conclusions}

To the best of our knowledge, the present study is the only series that assessed the feasibility of laminar screws in the sub-axial cervical spine in an Indian population. We found that Indian patients, by virtue of genetic and ethnic variations, have smaller anatomical dimensions that make them unsuitable for laminar screws in the subaxial cervical spine, barring C7, contrary to reports from western and south Asian countries. These findings suggest that standard implant dimensions need to be altered and supplemented by biomechanical studies for this technique to be successful in Indian populations, and such alterations may include a smaller diameter and length screws that are custom built for use in this technique.

\section{Conflict of Interest}

No potential conflict of interest relevant to this article was reported.

\section{Acknowledgments}

This study was supported by Research grant from AO Spine India.

\section{References}

1. Hedequist DJ, Emans JB. Cervical spine instrumentation in children. J Am Acad Orthop Surg 2016;24:370-8.

2. Cheung KM, Mak KC, Luk KD. Anterior approach to cervical spine. Spine (Phila Pa 1976) 2012;37:E297302.

3. Heller JG, Silcox DH 3rd, Sutterlin CE 3rd. Complications of posterior cervical plating. Spine (Phila $\mathrm{Pa}$ 1976) 1995;20:2442-8.

4. Fehlings MG, Cooper PR, Errico TJ. Posterior plates in the management of cervical instability: long-term results in 44 patients. J Neurosurg 1994;81:341-9.

5. Abumi K, Itoh H, Taneichi H, Kaneda K. Transpedicular screw fixation for traumatic lesions of the middle and lower cervical spine: description of the techniques and preliminary report. J Spinal Disord 1994;7:19-28.

6. Abumi K, Kaneda K. Pedicle screw fixation for nontraumatic lesions of the cervical spine. Spine (Phila 
Pa 1976) 1997;22:1853-63.

7. Abumi K, Shono Y, Taneichi H, Ito M, Kaneda K. Correction of cervical kyphosis using pedicle screw fixation systems. Spine (Phila Pa 1976) 1999;24:238996.

8. Nakashima H, Yukawa Y, Imagama S, et al. Complications of cervical pedicle screw fixation for nontraumatic lesions: a multicenter study of 84 patients. J Neurosurg Spine 2012;16:238-47.

9. Kast E, Mohr K, Richter HP, Borm W. Complications of transpedicular screw fixation in the cervical spine. Eur Spine J 2006;15:327-34.

10. Kretzer RM, Hu N, Kikkawa J, et al. Surgical management of two- versus three-column injuries of the cervicothoracic junction: biomechanical comparison of translaminar screw and pedicle screw fixation using a cadaveric model. Spine (Phila Pa 1976) 2010;35:E948-54.

11. Kretzer RM, Chaput C, Sciubba DM, et al. A computed tomography-based feasibility study of translaminar screw fixation in the upper thoracic spine. J Neurosurg Spine 2010;12:286-92.

12. Wang MY. Cervical crossing laminar screws: early clinical results and complications. Neurosurgery 2007;61(5 Suppl 2):311-5.

13. Chern JJ, Chamoun RB, Whitehead WE, Curry DJ, Luerssen TG, Jea A. Computed tomography morphometric analysis for axial and subaxial translaminar screw placement in the pediatric cervical spine. J Neurosurg Pediatr 2009;3:121-8.

14. Hong JT, Sung JH, Son BC, Lee SW, Park CK. Significance of laminar screw fixation in the subaxial cervical spine. Spine (Phila Pa 1976) 2008;33:1739-43.

15. Jea A, Johnson KK, Whitehead WE, Luerssen TG. Translaminar screw fixation in the subaxial pediatric cervical spine. J Neurosurg Pediatr 2008;2:386-90.

16. Benke MT, O’Brien JR, Turner AW, Yu WD. Biomechanical comparison of transpedicular versus intra- laminar C2 fixation in C2-C6 subaxial constructs. Spine (Phila Pa 1976) 2011;36:E33-7.

17. Shin SI, Yeom JS, Kim HJ, Chang BS, Lee CK, Riew KD. The feasibility of laminar screw placement in the subaxial spine: analysis using 215 three-dimensional computed tomography scans and simulation software. Spine J 2012;12:577-84.

18. Alvin MD, Abdullah KG, Steinmetz MP, et al. Translaminar screw fixation in the subaxial cervical spine: quantitative laminar analysis and feasibility of unilateral and bilateral translaminar virtual screw placement. Spine (Phila Pa 1976) 2012;37:E745-51.

19. Wright NM. Posterior C2 fixation using bilateral, crossing C2 laminar screws: case series and technical note. J Spinal Disord Tech 2004;17:158-62.

20. Srivastava A, Nanda G, Mahajan R, et al. Computed tomography-based occipital condyle morphometry in an Indian population to assess the feasibility of condylar screws for occipitocervical fusion. Asian Spine J 2017;11:847-53.

21. Srivastava A, Mahajan R, Nanda A, et al. Morphometric study of $\mathrm{C} 1$ pedicle and feasibility evaluation of $\mathrm{C} 1$ pedicle screw placement with a novel clinically relevant radiological classification in an Indian population. Asian Spine J 2017;11:679-85.

22. Acharya S, Dorje T, Srivastava A. Lower dorsal and lumbar pedicle morphometry in Indian population: a study of four hundred fifty vertebrae. Spine (Phila $\mathrm{Pa}$ 1976) 2010;35:E378-84.

23. Xu R, Burgar A, Ebraheim NA, Yeasting RA. The quantitative anatomy of the laminas of the spine. Spine (Phila Pa 1976) 1999;24:107-13.

24. Cardoso MJ, Dmitriev AE, Helgeson MD, et al. Using lamina screws as a salvage technique at C-7: computed tomography and biomechanical analysis using cadaveric vertebrae: laboratory investigation. J Neurosurg Spine 2009;11:28-33. 